\title{
Erratum to: Loneliness and Social Support in Adolescent Boys with Attention Deficit Hyperactivity Disorder in a Special Education Setting
}

Mette Elmose $\mathbb{C}^{1} \cdot$ Mathias Lasgaard ${ }^{1,2}$

Published online: 13 July 2017

(C) Springer Science+Business Media, LLC 2017

Erratum to: J Child Fam Stud (2017) DOI 10.1007/s10826-017-0797-2

The original version of this article unfortunately contained a mistake. One of the affiliations was incorrect for the author Mathias Lasgaard. The second affiliation should read as:

"DEFACTUM, Central Denmark Region, Aarhus N, Denmark".

The online version of the original article can be found at doi:10.1007/ s10826-017-0797-2.

Mette Elmose

melandersen@health.sdu.dk

1 Department of Psychology, University of Southern Denmark, Campusvej 55, DK-5230 Odense M, Denmark

2 DEFACTUM, Central Denmark Region, Aarhus N, Denmark 